\title{
Exploration of food materials and components showing the suppressing effect on absorption of strontium and the promoting effect on excretion of cesium in vivo
}

\author{
Yuya Uehara, Kana Ishizuka, Yuko Shimamura, Michiko Yasuda, Kayoko Shimoi and Shuichi Masuda* \\ School of Food and Nutritional Sciences, University of Shizuoka, Japan
}

\begin{abstract}
In March 2011, enormous radioactive materials, mainly ${ }^{137} \mathrm{Cs},{ }^{129} \mathrm{I},{ }^{90} \mathrm{Sr}$ and so on were released from the Fukushima Daiichi nuclear power plant after The Great East Japan Earthquake. Tap water, raw milk, vegetables, mushrooms, fruit, nuts, seaweed, marine invertebrates, fish, beef, wild animal meat, brown rice, wheat, tea leaves and other foodstuffs were contaminated by many radionuclides. In particular, when we eat foods contaminated by radioactive materials, it is thought that internal radiation exposure may cause and increase cancer risk. This study was performed to search food materials and components showing an inhibitory effect of strontium absorption and promotive effect of cesium excretion for the reduction of internal radiation exposure. In mice groups given kelp and laminaran, the concentrations of strontium in femurs of mice administrated with strontium chloride were significantly decreased compared with the control group (the only-strontium-chloride treated group). It was suggested that kelp and laminaran may inhibit the gastrointestinal absorption of $\mathrm{Sr}$ in vivo. We examined promoting effects of samples showing diuretics on cesium excretion into urine of mice. The Cs excretion ratio into urine was significantly increased by orally administration of coffee and theophylline compared with the only-cesium-chloride administered group. Our results indicate that these food materials and components can be useful tools to prevent internal radiation exposure by cesium and strontium.
\end{abstract}

\section{Introduction}

Large amounts of radioactive materials (mainly ${ }^{137} \mathrm{Cs},{ }^{129} \mathrm{I},{ }^{90} \mathrm{Sr}$ and so on) were released from the Fukushima Daiichi nuclear power plant after The Great East Japan Earthquake and the following nuclear accident and tsunami on March 11, 2011. The amount of released radioactive cesium and strontium to the atmosphere by this accident were estimated to be $3.3 \times 10^{16}, 2.1 \times 10^{15} \mathrm{~Bq}$, respectively [1]. Enormous radionuclides released from the power plant contaminated various foods and drinks, such as vegetables, milk, meats, eggs, fishes and drinking water [2]. Radiation exposure causes serious problems to human health and life. X-rays and gamma rays from radioactive materials are known human carcinogens (cancer-causing agents). The people exposed to radioactive materials have higher cancer risks, such as multiple myeloma, thyroid cancer, bladder cancer, breast cancer and so on. It is reported that the cancer risk was the highest for those exposed as children. In particular, internal radiation exposure is a very high risk, because radioactive materials continuously produce radiation inside the body. Therefore, it is a serious problem that humans are exposed to radiation from inside the body for a longtime by eating these contaminated foods.

${ }^{137} \mathrm{Cs}$ has a long physical half-life (30.2 years) [3], so health hazard by radiation continues for a long time. Since Cs belongs to the alkali metal group and has chemical properties similar to those of potassium (K), Cs shows similar biokinetics to $\mathrm{K}$ and distributes through the whole body uniformly as K [4]. Because the biological half-life of Cs is approximately 110 days, internal exposure by ${ }^{137} \mathrm{Cs}$ continues for three months when humans intake food contaminated by ${ }^{137} \mathrm{Cs} .{ }^{90} \mathrm{Sr}$ is also one of the most dangerous radioactive materials. Because of the long physical half-life (28.9 years) of ${ }^{90} \mathrm{Sr}$, the risk of health hazards, such as cancer, increases by internal radiation exposure of ${ }^{90} \mathrm{Sr}[5,6]$.
Strontium, which is classified as an alkaline earth metal in the periodic table, can chemically replace calcium in the bone and remain there for a long time [7]. Therefore, internal radiation exposure, depending on intake of foods contaminated by radioactive materials such as ${ }^{137} \mathrm{Cs}$ and ${ }^{90} \mathrm{Sr}$, which have long half-lives in vivo, induces serious disease and cancer to humans.

Presently, a drug called Radiogardase is used to prevent our bodies from internal radiation exposure. Radiogardase contains ferric ferrocyanide $\left(\mathrm{Fe}_{4}\left[\mathrm{Fe}(\mathrm{CN})_{6}\right]_{3}\right)$, which is an active ingredient, generally called Prussian blue. Prussian blue binds Cs in gut lumen by an ionic changing reaction between $\mathrm{Fe}$ and $\mathrm{Cs}$ [8]. Treatment with Prussian blue increases the ${ }^{137} \mathrm{Cs}$ excretion in feces. Prussian blue is non-toxic. However, it is reported that Prussian blue shows the side effect of constipation $[9,10]$. Therefore, enhanced health hazard might be caused due to local radiation exposure by ${ }^{137} \mathrm{Cs}$ binding with Prussian blue in the intestinal tract because of constipation induced by Prussian blue. There are some reports about the chemicals exhibiting a reduction effect on internal exposure induced by radioactive materials. It was reported that sodium alginate (ALA-Na) decreases the accumulation amount of $\mathrm{Sr}$ in the human body to one-eighth [11]. Moreover, daily intake of ALA-Na (10 g/body) shows the reaction of the body to protect against

Correspondence to: S. Masuda, Graduate School of Nutritional and Environmental Sciences, University of Shizuoka, 52-1 Yada, Suruga-ku, Shizuoka 422-8526, Japan, Tel: +81(54) 2645528, Fax: Tel: +81(54) 2645528, E-mail: masudas@u-shizuoka-ken.ac.jp

Key words: cesium, strontium, radioactive materials, internal radiation exposure

Received: December 10, 2016; Accepted: December 23, 2016; Published: December 26, 2016 
radiation damage by decreasing the absorption of radioactive $\mathrm{Sr}$ [12]. International Atomic Energy Agency (IAEA) recommends patients who were exposed to large amounts of radioactive $\mathrm{Sr}$ to use ALA-Na [13]. However, because ALA-Na is sodium salt of alginate, excess intake of ALA-Na may potentially cause hypertension. Therefore, calcium salt of alginate (ALA-Ca) was also used for protection of internal radiation exposure by inhibiting absorption of Sr in vivo. It was reported that ALA-Ca reduced absorption and enhanced excretion of Sr [14]. ALA$\mathrm{Ca}$ also decreases absorptivity and promotes the excretion of Cs. Additionally, in the Chernobyl nuclear power accident; it was shown that apple pectin, which is polysaccharide as alginic acid, reduced ${ }^{137} \mathrm{Cs}$ levels in children $[15,16]$. It is suggested that polysaccharides, such as alginate and apple pectin, are useful ingredients to be able to reduce the internal radiation exposure of radioactive materials.

In addition, when it is exposed to radioactive Cs in our body, we must rapidly excrete Cs from the body. Because Cs is excreted mainly into urine (approximately $85 \%$ ) [4], it is considered to be effective to enhance urine excretion of Cs by the diuretic action of chemicals. It was reported that chlorothiazide and acetazolamide, known as diuretic, can enhance Cs excretion into urine $[17,18]$. Therefore, it is thought that the chemicals showing diuretic effects are also useful to excrete radioactive Cs from the body.

In this study, we explored various food materials and components that show inhibiting effects of absorption of $\mathrm{Sr}$ and promote excretion effects of Cs through urine without side effects and toxicity for the reduction of internal exposure.

\section{Materials and methods}

\section{Chemicals}

Cesium chloride $(\mathrm{CsCl})$ and strontium chloride $\left(\mathrm{SrCl}_{2}\right)$ were purchased from Wako Pure Chemical Industries, Ltd. (Osaka, Japan). Nitric acid (68\%) was bought from TAMA Chemical CO., Ltd. (Kanagawa, Japan). Cesium standard solution (1000 ppm), strontium standard solution (1000 ppm) and yttrium standard solution (1000 ppm) were purchased from Wako Pure Chemical Industries, Ltd. (Osaka, Japan).

\section{Test samples}

Sodium-alginate (ALA-Na) and calcium-alginate (ALA-Ca) were purchased from KIMICA Co. (Tokyo, Japan). Caffeine, theophylline and methyl cellulose (MC) were bought from Wako Pure Chemical Industries, Ltd. (Osaka, Japan). Sodium-carboxyl methyl cellulose (CMC-Na) was purchased from Sigma-Aldrich Japan Co. (Tokyo, Japan). Chondroitin sulfate (ChS) from shark, mainly containing chondroitin sulfate C (chondroitin 6-sulfate), was obtained from Maruha Nichiro Corporation (Tokyo, Japan). Kelp was bought from a supermarket in Shizuoka city, Japan and was freeze-dried with an FDU-2100 (Tokyo Rikakikai Co., Ltd., Tokyo, Japan) as samples. Laminaran was purchased from Tokyo Chemical Industry Co., Ltd. (Tokyo, Japan). These samples were prepared at the following concentration using distilled water to examine the inhibitory effects of strontium absorption: ALA-Na; $5 \mathrm{mg} / \mathrm{ml}$, ALA-Ca; $5 \mathrm{mg} / \mathrm{ml}$, ChS; 80 $\mathrm{mg} / \mathrm{ml}, \mathrm{MC} ; 12 \mathrm{mg} / \mathrm{ml}$, laminaran; $500 \mathrm{mg} / \mathrm{ml}$, kelp; $150 \mathrm{mg} / \mathrm{ml}$, CMC$\mathrm{Na} ; 50 \mathrm{mg} / \mathrm{ml}$.

Green tea leaves $(5.0 \mathrm{~g})$ were brewed with hot water $\left(80^{\circ} \mathrm{C}, 200 \mathrm{ml}\right)$ and stood for one min. Green tea extract was freeze-dried and used as samples. One gram of instant coffee was suspended in $100 \mathrm{ml}$ of hot water $\left(90^{\circ} \mathrm{C}\right)$. The aqueous solutions obtained were freeze-dried and used as samples. Caffeine, theobromine and theophylline were purchased from Tokyo Chemical Industry Co., Ltd. (Tokyo, Japan). These samples were prepared at the concentration of $2.5 \mathrm{mg} / \mathrm{mL}$ using distilled water to investigate the promoting excretion effect of Cs through urine.

\section{Animals and treatment}

The animal study was carried out according to the guidelines of animal experiments at the University of shizuoka. Male ICR mice (five weeks of age, weight range of 28-32 g) were purchased from Japan SLC, Inc (Shizuoka, Japan), and were acclimatized for one week before the experiment began. During the period and throughout the experiment, the mice were housed in a cage with clean chip bedding in an animal room maintained under controlled conditions (temperature of $23 \pm 1^{\circ} \mathrm{C}$, humidity of $55 \pm 5^{\circ} \mathrm{C}$ ) with a $12 \mathrm{~h} \mathrm{light/dark}$ cycle. Mice were given a standard rodent diet of CE-2 (Oriental Yeast Co., Ltd. (Tokyo, Japan)) ad libitum. The mice were randomly allocated to the experimental groups (five mice / group).

To examine the inhibitory effects of food materials and components on $\mathrm{Sr}$ absorption, mice were orally administered simultaneously with each test sample and with the $\mathrm{SrCl}_{2}$ solution $(20 \mathrm{mg} / 10 \mathrm{~mL} / \mathrm{kg}$ body weight). Distilled water was administered as a positive control. After 24 hours from the administrations, the mice were dissected in order to get both femoral bones. Both femoral bones were dissolved in $68 \% \mathrm{HNO}_{3}$ using microwave heating. Sr concentration in the bone solution was determined by ICP-MS (Varian 810/820-MS, Varian Medical Systems, Inc., Tokyo, Japan).

To examine the promoting effect of food materials and components on Cs excretion, mice were randomized into the experimental groups (five mice / group) and orally administrated with one $\mathrm{mg} / 10 \mathrm{ml} / \mathrm{kg}$ of body weight of the $\mathrm{CsCl}$ solution. After 30 minutes, we administrated sample solutions at the dose of $10 \mathrm{ml} / \mathrm{kg}$ of body weight. Distilled water was administered as a positive control. After administrations of sample solutions, mice were housed in metabolic cages for $72 \mathrm{~h}$. Urine of treated mice was collected three times every $24 \mathrm{~h}$ for three days. Three collected urine samples for 72 days were combined and diluted with distilled water. Diluted urine samples were dissolved in $68 \% \mathrm{HNO}_{3}$ with microwave heating. The Cs concentration in the urine sample was determined by ICP-MS (Varian 810/820-MS, Varian Medical Systems, Inc., Tokyo, Japan). Yttrium was used as an internal standard for the determination of Sr and Cs concentrations using ICP-MS analysis. ICP-MS limits of quantification (LOQ) for strontium and cesium were as follows; Cs: $0.05 \mathrm{ppb}$, Sr: $0.05 \mathrm{ppb}$. All samples were analyzed in triplicates.

\section{Statistical analysis}

Data are expressed as mean \pm S.D. Statistical comparisons were made using the Dunnett multiple comparison test. Values of $\mathrm{p}<0.05$ were considered significant.

\section{Results and discussion}

The relative strontium content rate in both mice femoral bones of the experimental groups treated with food materials and components compared with the positive control is shown in Figure 1. ALA-Ca, laminaran and kelp significantly decreased the $\mathrm{Sr}$ concentration in both femoral bones compared with the control group, $75.4 \%, 80.2 \%$ and $92.1 \%$, respectively (Figure 1). Kelp is a common food in Japan, China and Korea, and is usually eaten as a flavored broth or a savory garnish for meals. Kelp contains alginate and laminaran as a fiber source [19]. It 


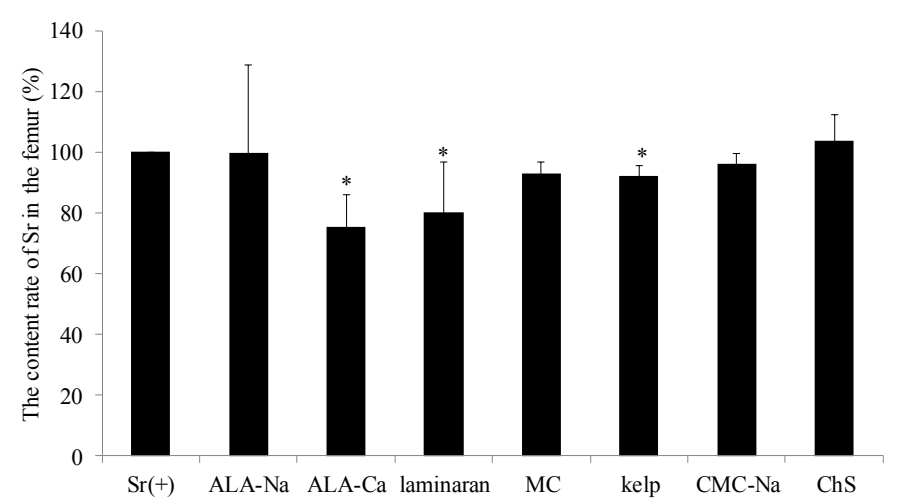

Figure 1. The content rate of $\mathrm{Sr}$ in femur of mice in each experimental group. The $\mathrm{Y}$ axis represents the content rate of $\mathrm{Sr}$ in the femur of both feet calculated relative to the $\mathrm{Sr}(+)$ group, which ingested distilled water. The data represents mean \pm S.D. $(\mathrm{n}$ $=5)$. The significance of difference between the control group and ALA-Na, ALA-Ca, Laminaran, MC, Kelp, CMC-Na and ChS groups was determined by the Dunnett multiple comparison test. $* p<0.05$

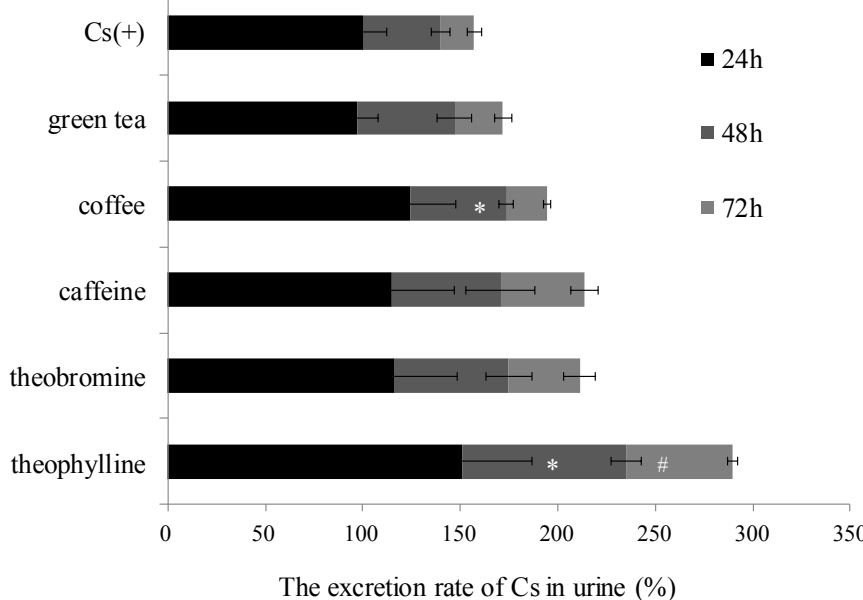

Figure 2. The excretion rate of $\mathrm{Cs}$ in urine of mice in each experimental group The excretion rate of $\mathrm{Cs}$ in urine was calculated by comparing with the amount of $\mathrm{Cs}$ in the urine of the $\mathrm{Cs}(+)$ group. The data represent mean \pm S.D. $(\mathrm{n}=5)$. The significance of difference between the $\mathrm{Cs}(+)$ group and green tea, coffee, caffeine, theobromine and theophylline groups was determined by the Dunnett multiple comparison test. $* p<0.05$ vs $\mathrm{Cs}(+)$ at 24 hours. ${ }^{*} p<0.05$ vs $\mathrm{Cs}(+)$ at 48 hours. ${ }^{*} p<0.05$ vs $\mathrm{Cs}(+)$ at 72 hours.

has been reported that alginate enhances the excretion of $\mathrm{Sr}$ and inhibits reabsorption of $\mathrm{Sr}$ at the gastrointestinal tract [14]. It was suggested that the inhibitory effects of kelp on the Sr absorption may be induced by alginate and laminaran contained in kelp. Additionally, kelp is an iodine-rich food [20]. Iodine tablets are used to protect accumulation of radioactive ${ }^{131} \mathrm{I}$ in the thyroid gland and should be stocked by local governments in a $30 \mathrm{~km}$ zone around nuclear power plants in Japan. Also, it has been reported that $\beta$ glucans, such as laminaran, have immunostimulating activity and protect the body from radiation $[21,22]$. So, it was demonstrated that kelp may be a useful foodstuff for the prevention of internal radiation exposure because kelp can inhibit $\mathrm{Sr}$ absorption and contain abundant iodine. Idota et al. reported that ALA-Na enhances excretion of $\mathrm{Sr}$ in vivo test using rats. In their study, rats were given a diet containing ALA-Na for two weeks. However, in our study, ALA-Na did not show inhibitory effects on Sr absorption. We orally administered test samples as a single dose to mice in our study. Therefore, the difference between data in our study and theirs may be induced by the administration condition of samples. The dose of $\mathrm{Sr}$ administered to mice in our study was a very large amount relative to the possible amount by internal radiation exposure of radioactive Sr. Because a certain amount of Sr is present in human bone, it is difficult to distinguish between administered $\mathrm{Sr}$ and originally accumulating $\mathrm{Sr}$ in vivo. It is necessary to investigate the effects of samples to estimate absorption effects using the radioactive isotope $\mathrm{Sr}$.

The relative Cs excretion ratio into urine of mice in each experimental group treated with food materials and components is shown in Figure 2. The relative Cs excretion ratio of every 24 hour period in each group was calculated when the Cs concentration in urine of a positive control, after administration of 24 hours, was $100 \%$. Coffee and theophylline significantly increased the Cs excretion rate into the urine at the end of the 24 hour period, respectively (124\% and 151\%). Additionally, theophylline significantly increased the Cs excretion ratio in urine after 48 and 72 hours compared with the positive control group. Caffeine and theobromine also showed the tendency increasing Cs excretion rate into the urine after 24 hours, respectively (115\% and $116 \%$ ). All sample-treated groups increased the excretion rate of Cs into the urine at 48 hours and 72 hours. Methylxanthine derivatives, such as caffeine, theobromine and theophylline, have diuretics effects. Theophylline shows the strong diuretic action in the order of diuretic action followed by, theobromine and caffeine [23,24]. Now, theophylline is used in therapy for respiratory diseases, such as chronic obstructive pulmonary disease. In this study, theophylline might be used as a medical countermeasure together with radiogardase. Because theophylline is contained in traces in black tea [25], black tea may induce excretion of Cs. Cacao containing theobromine could also show promoting effects on Cs excretion. Thus, it was suggested that promoting effects on Cs excretion might be induced by diuretics action of these samples. Green tea did not show any Cs excretion effects. As for the reason for this result, the caffeine concentration in coffee is more than that in green tea [26]. It is thought that coffee containing various components, such as chlorogenic acid and diterpenes, show a synergistic diuretic effect in addition to caffeine. Potassium, which is one of the essential minerals, is also excreted by the diuretic effect at the same time. It is reported that caffeine-rich beverages induce hypokalemia because of potassium excretion induced by their diuretic activity [文献]. When chemicals showing diuretic effects are used to excrete radioactive Cs, it needs to be considered whether mineral balance is maintained for human health.

In this study, we found some food materials and components showing the suppressing effect on absorption of strontium and the promoting effect on excretion of cesium in vivo. We should estimate their adequate amounts without toxicity induction when they are used to protect internal exposure by radioactive materials.

\section{Conclusion}

In this study, we investigated food materials and components that inhibit Sr absorption and promote Cs excretion into urine for the reduction of internal exposure by radioactive materials. It was found that laminaran and kelp might be effective to inhibit $\mathrm{Sr}$ absorption in vivo. It was also demonstrated that coffee and theophylline have the ability to promote Cs excretion from the body. From these results, it was demonstrated that these food materials and components might be useful tools to protect internal exposure by radioactive materials.

\section{References}

1. Sato I, Kudo H, Tsuda S (2011) Removal efficiency of water purifier and adsorbent for iodine, cesium, strontium, barium and zirconium in drinking water. J Toxicol Sci 36: 829-834. [Crossref]

2. Tsubokura M, Kato S, Nomura S, Gilmour S, Nihei M, et al. (2014) Reduction of 
Uehara Y (2016) Exploration of food materials and components showing the suppressing effect on absorption of strontium and the promoting effect on excretion of cesium in vivo

high levels of internal radio-contamination by dietary intervention in residents of areas affected by the Fukushima Daiichi nuclear plant disaster: a case series. PLoS One 9: e100302. [Crossref]

3. Paller MH, Jannik GT, Fledderman PD (2008) Changes in 137Cs concentrations in soil and vegetation on the floodplain of the Savannah River over a 30 year period. J Environ Radioact 99: 1302-1310. [Crossref]

4. Leggett RW, Williams LR, Melo DR, Lipsztein JL (2003) A physiologically based biokinetic model for cesium in the human body. Sci Total Environ 317: 235-255. [Crossref]

5. O'Hara MJ, Burge SR, Grate JW (2009) Automated radioanalytical system for the determination of $90 \mathrm{Sr}$ in environmental water samples by $90 \mathrm{Y}$ cherenkov radiation counting. Anal Chem 81: 1228-1237. [Crossref]

6. Steinhauser G, Schauer V, Shozugawa K (2013) Concentration of strontium-90 at selected hot spots in Japan. PLoS One 8: e57760. [Crossref]

7. Goudarzi M, Weber WM, Chung J, Doyle-Eisele, Melo DR, et al. (2015) Serum dyslipidemia is induced by internal exposure to strontium-90 in mice, lipidomic profiling using a data-independent liquid chromatography-mass spectrometry approach. J Proteome Res 14: 374-384. [Crossref]

8. Le Gall B, Taran F, Renault D, Wilk JC, Ansoborlo E (2006) Comparison of Prussian blue and apple-pectin efficacy on 137Cs decorporation in rats. Biochimie 88: 18371841. [Crossref]

9. Thompson DF, Church CO (2001) Prussian blue for treatment of radiocesium poisoning. Pharmacotherapy 21: 1364-1367. [Crossref]

10. Kobayashi N, Yamamoto Y, Akashi M (1998) Prussian blue as an agent for decontamination of $137 \mathrm{Cs}$ in radiation accidents. Japan Health Physics Society 33 323-330.

11. Hesp R, Ramsbottom B (1965) Effect of sodium alginate in inhibiting uptake of radiostrontium by the human body. Nature 208: 1341-1342. [Crossref]

12. Nishimura Y, Wui IS, Kim KY, Watari K, Imai K, et al. (1991) Effect of chitosan and alginate on the biokinetics of radiostrontium in rats. Radioisotopes 40: 244-247.

13. Radiation protection in the design of radiotherapy facilities (2006) Safety Reports Series, No. 47, IAEA, Vienna.

14. Idota Y, Harada H, Tomono T, Morimoto K, Kobayashi S, et al. (2013) Alginate enhances excretion and reduces absorption of strontium and cesium in rats. Biol Pharm Bull 36: 485-491. [Crossref]
15. Nesterenko VB, Nesterenko AV, Babenko VI, Yerkovich TV, Babenko IV (2004) Reducing the 137Cs-load in the organism of "Chernobyl" children with applepectin. Swiss Med Wkly 134: 24-27. [Crossref]

16. Bandazbevskaya GS, Nesterenko VB, Babenko VI, Babenko IV, Yerkovich TV, et al (2004) Relationship between Caesium (137Cs) load, cardiovascular symptoms, and source of food in "Chernobyl" children - preliminary observations after intake of oral apple pectin. Swiss Med Wkly 134: 725-729. [Crossref]

17. Harrison J, MCNeill KG (1963) Effect Of Chlorothiazide On Cesium-137 Excretion In Human Subjects. Can Med Assoc J 89: 1266-1269. [Crossref]

18. Sastry BV, Bush MT (1964) Enhancement Of The Renal Excretion Of Cesium-137 In Rats Treated With Acetazolamide And Related Compounds. J Pharmacol Exp Ther 143: 30-41. [Crossref]

19. Yamagishi A, Aoe S (2013) Effect of organic acids and organic acid salts on softening of Konbu. Int J Hum Cult Stud 23: 176-178.

20. Martinelango PK, Tian K, Dasgupta PK (2006) Perchlorate in seawater: bioconcentration of iodide and perchlorate by various seaweed species. Anal Chim Acta 567: 100-107. [Crossref]

21. Yoshimura A, Hasegawa T, Monzen H, Tawaraya H, Takahashi T (2003) Antitumor and Radiation Protection Effect of ?-1,3-D-Glucan Extracted from Yeast (Saccharomyces cerevisiae). Radioisotopes 52: 687-691.

22. Lee JY, Kim YJ, Kim HJ, Kim YS, Park W (2012) Immunostimulatory effect of laminarin on RAW 264.7 mouse macrophages. Molecules 17: 5404-5411. [Crossref]

23. Takeuchi K, Kogo H, Aizawa Y (1981) [Effect of methylxanthines on urinary prostaglandin $\mathrm{E}$ excretion of rats acutely loaded with salt and water (author's transl)]. Nihon Yakurigaku Zasshi 77: 427-434. [Crossref]

24. Rieg T, Steigele H, Schnermann J, Richter K, Osswald H, et al. (2004) Requiremen of Intact Adenosine A1 Receptors for the Diuretic and Natriuretic Action of the Methylxanthines Theophylline and Caffeine. J Pharmacol Exp Therm 313: 403-409. [Crossref]

25. Fukuhara K, Matsuki Y, Nanbara T (1984) Simultaneous determination of theobromine, theophylline and coffeine in foods by high performance liquid chromatography. Food Hyg Saf Sci 26: 208-212.

26. Kunugi A, Aoki T, Kunugi S (1988) Determination of caffaine in coffee, black tea an green tea by high performance liquid chromatography. Food Hyg Saf Sci 29: 136-140.

Copyright: (C2016 Uehara Y. This is an open-access article distributed under the terms of the Creative Commons Attribution License, which permits unrestricted use, distribution, and reproduction in any medium, provided the original author and source are credited. 